supplements, as in the case of vita$\min$ A. Yet, other studies suggest that the main impact of poverty extends beyond diet and cannot be addressed through improved nutrition alone. Such is the experience from Peru, where a study by the Tuberculosis Research Group at Imperial College (London, UK) has been evaluating whether dietary supplementation with vitamin $A$, vitamin $D$ and zinc reduces the risk of tuberculosis. The study recruited 800 healthy people in Peru who were at risk of contracting the disease for a randomized, blinded, placebo-controlled trial, which is approaching completion. The results are yet to be published, but preliminary data suggest that supplementation has failed to protect against tuberculosis, according to Carlton Evans, a research career development fellow in Clinical Tropical Medicine at the Wellcome Centre for Clinical Tropical Medicine at the College, and leader of the study.

\section{...although Evans agrees that nutrition is important, he argues that poverty is complex and that diseases cannot be cured or prevented just by distributing supplements}

"We have found very clearly that the main determinants of which of these people go on to get tuberculosis are very profoundly socioeconomic. The strongest single factor predicting tuberculosis is not having a cell phone." Factors such as overcrowding, despair, poor ventilation, stress and the other negative aspects of poverty seem to be at least as important as nutrition. Such conclusions are perhaps not too surprising. The same group began a second study in 2007 to ascertain whether socioeconomic interventions could reduce the incidence of tuberculosis. This work, called Innovative Socioeconomic Interventions Against Tuberculosis (ISIAT), recruited 2,078 people in 311 households in which there were newly diagnosed tuberculosis patients. The researchers conducted visits, held workshops, formed partnerships with existing organizations and provided low-level economic relief, such as by making small lines of credit available. The study is about to publish preliminary findings indicating that these measures can prevent tuberculosis more effectively than micronutrient supplementation.
Thus, although Evans agrees that nutrition is important, he argues that poverty is complex and that diseases cannot be cured or prevented just by distributing supplements. He also reiterated that sometimes giving supplements is exactly the wrong thing to do. "It has been shown, for example, that giving iron to people with malaria can cause them to die, because if someone is very frail, spicing up their immune system can be fatal."

The story of nutrition is complex, but a new, more complete picture is emerging. In regions in which micronutrient deficiency is rare, the focus of health professionals, nutrition experts and scientists is on producing and promoting foods containing appropriate forms and proportions of micronutrients. Although the convenience of popping a couple of pills with breakfast appeals to fast-paced modern societies, doing so is not usually an effective way to supplement the diet. In areas of poverty where deficiencies occur, crops that contain balanced proportions of micronutrients are effectivemore so than dietary supplements-but improved nutrition must be complemented by socioeconomic measures that address the other causes of disease. Finally, there is a new field of research emerging: what role do micronutrients have in drug effectiveness and safety? The proof of the micronutrient, as they say, will be in the eating.

\section{REFERENCES}

Frank J (2005) Beyond vitamin E supplementation: an alternative strategy to improve vitamin $\mathrm{E}$ status. J Plant Physiol 162: 834-843

Haywood S, Simpson DM, Ross G, Beynon RJ (2005) The greater susceptibility of North Ronaldsay sheep compared with Cambridge sheep to copper-induced oxidative stress, mitochondrial damage and hepatic stellate cell activation. J Comp Pathol 133: 114-127

Pauling L (1976) Vitamin C, the Common Cold and the Flu. San Francisco, CA, USA: WH Freeman

Pauling L (1986) How to Live Longer and Feel Better. New York, NY, USA: WH Freeman

Rosado JL et al (2009) The quantity of zinc absorbed by adult women is enhanced by biofortification. J Nutr 139: 1920-1925

Sommer A, Tarwotjo I, Djunaedi E, West KP Jr, Loeden AA, Tilden R, Mele L (1986) Impact of vitamin A supplementation on childhood mortality. A randomized controlled community trial. Lancet 24: 1169-1173

Spears JW (2003) Trace mineral bioavailability in ruminants. J Nutr 133: 1506S-1509S Tanumihardjo SA et al (2008) Food based approaches for ensuring adequate vitamin A nutrition. Comp Rev Food Sci Safety 7: 373-381

\section{Philip Hunter is a freelance journalist} in London, UK.

EMBO reports (2011) 12, 307-310.

doi:10.1038/embor.2011.42

\title{
Needles in a haystack
}

\author{
Genomic tools have become powerful tools for conservation biologists \\ to monitor the spread of invasive species
}

\section{Howard Wolinsky}

lot n the late 1960s, an Air France pilot and his family took a holiday in swampy Louisiana in the southeastern USA and were intrigued by the giant bullfrogs, Rana catesbeiana. The family introduced a dozen of the animals to a pond in the Bordeaux region of southwestern France, inadvertently starting a major invasion that affected thousands of lakes and creeks with devastating effects on the native fauna. "They eat everything and if you go to a pond where there are bullfrogs, there are no other amphibians [...] because bullfrogs prey on other animals or because they are spreading a disease-chytridiomycosisthat is absent from some European areas," said conservation biologist Francesco Ficetola of the Department of Environmental Sciences at the University of MilanoBicocca in Italy. "There was nothing like them in Europe," he added.

As part of his postdoctoral research, Ficetola studied the frog invasion in Europe at the Universite de Savoie and the University of Grenoble in France. To monitor their distribution, he pioneered the use of environmental DNA (eDNA) to detect $R$. catesbeiana without observing the 


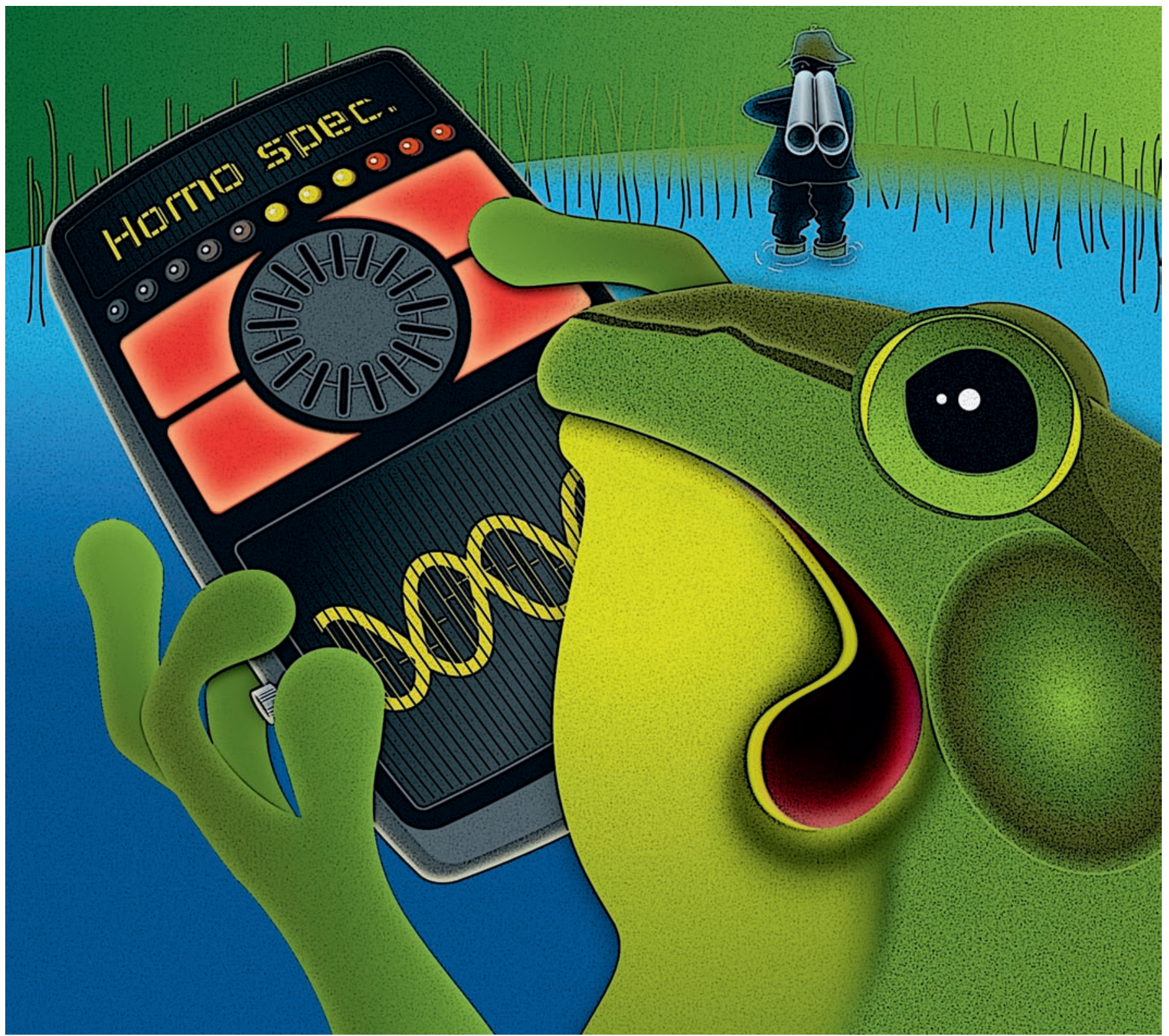

animals themselves. He and his colleagues took water samples, extracted eDNA and used primers monomorphic to nearly 400 bullfrog samples to demonstrate their presence in wetlands, even in low densities.

"The significance was that we were able to detect the presence of the species without seeing or hearing the species," Ficetola said. The eDNA technique has further potential: "As the environment can retain the molecular imprint of inhabiting species, our approach allows the reliable detection of secretive organisms in wetlands without direct observation. Combined with massive sequencing and the development of DNA barcodes that enable species identification, ...molecular and genomic tools to identify, monitor and control invasive species have become increasingly sophisticated during the past five years...

this approach opens new perspectives for the assessment of current biodiversity from environmental samples" (Ficetola et al, 2008).

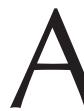
ccording to David Lodge, a biologist at the University of Notre Dame (South Bend, IN, USA), molecular and genomic tools to identify, monitor and control invasive species have become increasingly sophisticated during the past five years and are especially valuable in aquatic environments. "Hair traps and scat sampling have been used for mammals for a long time. You don't have to catch the lynx, for example. You just put a piece of wire or tape on a trail and you get a little bit of hair and then you do genetic analysis to figure out which species it is. With enough sampling and genetic sequencing, you could even estimate the number of individuals in a population," Lodge explained. Technological advances now make it possible to apply this technique to aquatic ecosystems to 
track everything from whales down to the smallest organisms.

Most invasive species eventually find their ecological niche among the natives, but some can turn into pests, particularly if the new environment does not pose any threats for them such as predators or diseases. The American bullfrog in Europe, the cane toad, Bufo marinus, in Australia, or the zebra mussel, Dreissena polymorpha, in the Great Lakes have all wreaked havoc on the environment and have had an impact on commercial interests. In addition to standard control measures - such as killing animals or halting their further migration with barriers - scientists have also explored biological methods of tracking and controlling invasive species, but it is only in the past few years that these have become efficient enough to find the proverbial needle in a haystack.

I $\mathrm{n}$ the USA, these genomic tools are being applied to track Asian carp species in the Mississippi, its tributary IIlinois river and the Great Lakes. The large, jumping carp have negative effects on the native fish and are even able to knock down boaters (http://www.youtube.com/ watch?v=yS7zkTnQVaM). Christopher Dionigi, assistant director for National Policy and Programs of the US National Invasive Species Council (Washington, DC, USA), a cooperative of federal agencies created in 1999, said, "They're large, they do jump out of the water, they can achieve very high densities in specific areas, and [have] impacted a lot of native fisheries, and also game fish." The silver and bighead carp are harvesting phytoplankton and zooplankton, which are dietary mainstays for many other species. Lodge described the carp as "aquatic cows" that outgrow their predators and compete with other species for food.

\section{In the USA, these genomic tools are being applied to track Asian carp species in the Mississippi, its tributary Illinois River and the Great Lakes}

Inspired by Ficetola's eDNA work and his own research to develop detection tools for species in the ballast water of ships, Lodge and his colleagues are using eDNA to tackle a raging political issue in the American Midwest: whether Asian carp are invading
Lake Michigan around Chicago-and potentially the rest of the Great Lakes-from the Mississippi River.

Neighbouring states, led by Michigan, have taken the US Army Corps of Engineers and the Chicago Metropolitan Water Reclamation District to court to get Chicago to close locks on the Chicago Sanitary and Ship Canal, which was built to divert Chicago's sewage away from Lake Michigan into the Mississippi instead. The main dispute is whether the canal allows the Asian carp to invade Lake Michigan.

\section{...Lodge and his colleagues are using eDNA to tackle a raging political issue in the American Midwest: whether Asian carp are invading Lake Michigan around Chicago...}

Since 2009, Lodge's group has been conducting a risk assessment for the Army Corps to determine whether carp and other invasive species are able to move through the canal into the Great Lakes. The team collected more than 1,000 surface water samples, extracted DNA and used markers specific for Hypophthalmichthys nobilis and H. molitrix (Jerde et al, 2011). Subsequently, commercial fishermen caught an adult bighead carp within $13 \mathrm{~km}$ of Lake Michigan, only $4 \mathrm{~km}$ upstream from the nearest positive eDNA detection.

"There has been a lot of hand-wringing about where the carp are. We wanted to see if we could detect the presence of Asian carp without even seeing them," Lodge explained. "The most important thing we found (using eDNA) was DNA of both species in many places on the lake side of the electric barriers that the Army Corps of Engineers maintains in the canal [to keep the carp out of the lake]".

He added that eDNA can help in early detection of invasive species, which is key to effective management on the basis of 'early detection, rapid response'. "Because eDNA evidence indicates that at least silver carp have entered Lake Michigan, surveillance is warranted within Great Lakes rivers that may be colonized and could support successful spawning," Lodge said. "The eDNA method appears well-suited to rapid surveys across the large spatial scale that will be required in the Great Lakes." He added that it might be possible to poison the carp when they aggregate to spawn.
N athan Bott, a molecular-diagnostic researcher at the South Australian Research and Development Institute (SARDI; Henley Beach, SA, Australia), is adapting a technique to extract DNA from soil to detect invasive species in the ballasts of ships. This approach involves identifying DNA from pests, some of which have the potential to destroy farmed or fished mussel, scallop and abalone. Bott has been working on assays for the Asian bag mussel, Musculista senhousia, northern Pacific sea star, Asterias amurensis, and European fan worm, Sabella spallanzanii.

He said SARDI is in the process of purchasing a 454 sequencer to verify positive samples. "The idea is if we are getting positives in the ports, and particularly if the species in question is considered a significant threat, the authorities would want to conduct further surveys." Bott explained that quantitative PCR can screen thousands of samples per day, and the 454 sequencer would be used to confirm the positives to deliver a rapid result. "If we can carry out a quick and relatively inexpensive experiment on the eDNA result with quantitative PCR using our 454, then we can save everyone a lot of time and money, and rather than concentrating on confirming the presence of the pest, a control strategy can be instigated."


nce an invasive species is identified, what can de done to remove it? The French took to shooting and trapping American bullfrogs, removing eggs and tadpoles and draining wetlands. The Americans built electrical fences to try to stop the Asian carp from entering the Great Lakes. The state of Illinois has even supported a fishing operation to catch Asian carp, shipping the fillets to China-a scheme that could potentially lead to perverse incentives to introduce more fish.

\section{...eDNA can help in early detection of invasive species, which is key to effective management on the basis of 'early detection, rapid response'}

Meanwhile, biologists are refining an old concept for species control that disrupts the ratio of sexes in order to control or even kill off invasive species. The basic ideacreating sterile males, mainly by using irradiation, and releasing them by the millions - is 
not new. Sterile males compete with wild males for the females but do not produce offspring. Repeated introductions of these populations can control or even wipe out whole populations. Since its first application in the 1950s, there have been several success stories, including eradication of the screw-worm fly (Cochliomyia hominivorax) in North America and control of several species of fruit flies.

\section{...biologists are refining an old concept for species control that disrupts the ratio of sexes in order to control or even kill off invasive species}

In recent years, the concept has been improved by using molecular and genetic approaches. Ron Thresher, a marine ecologist who researches invasive species for the Australian Commonwealth Scientific and Industrial Research Organization in Hobart, Tasmania, Australia, said that common carp_-bottom-feeders that foul water and dig up plants-were causing problems Down Under. However, he said that stakeholders, such as public and commercial fishing interests, resist biological controls_-introducing predators, parasites or genetically modified viruses to make carp sterile-because these could have unintended consequences.

As a result, his group has begun exploring another approach, while gently steering away from the transgenic controversies. "We've been careful to make it clear to people that we're using genetic-modification technology but it's not transgenic," he said. "What we're doing is taking a carp's native genes and basically rearranging them a little bit. So it's using wholly native fish genes at this point. This makes a large difference in terms of public acceptability."

Thresher said his group has been developing techniques that control gene activity with the goal of causing sterility in females or causing females to change sex. The approach has been proven in lab studies in zebra fish and is now being applied to carp. He estimates that it would take 50 years to eliminate the carp with this approach. "It's generation and time dependent," he said.

ike Thresher, John Teem, a molecular biologist at the Florida Department of Agriculture and Consumer Services (Tallahassee, FL, USA), is tinkering with fish genetics and hormones to develop a Trojan fish with two $\mathrm{Y}$ chromosomes that would cause a population to collapse over time.

Normally, a female has two $X$ chromosomes and males have an $X$ and a $Y$ chromosome; it is the $\mathrm{Y}$ chromosome that determines 'maleness'. Teem said his strategy would create female fish with two Y chromosomes. This fish, when introduced into a target invasive population, will begin to mate with normal males $(\mathrm{XY})$ producing only male progeny. Half of those males will be $Y Y$ males that will themselves mate and produce only male progeny.

"We're trying to change the sex ratio of the population so that there are more males and fewer females at each generation. By flooding the system with $Y$ chromosomes, more and more male fish are produced," Teem explained. "Ultimately, the population collapses when there are no more females." For a fish with a one-year mating cycle, he estimated that it would take 70 years to eradicate a population.

Production of $Y Y$ females involves selective breeding of fish that have been sex-reversed by hormone treatment as juveniles. The process uses techniques that are commonly employed in the aquaculture industry and does not rely on recombinant DNA technology. Teem said the approach could work on carp or other fish with an XY-chromosome sex determination, but he has been focusing on tilapia, which was introduced to control invasive aquatic plants in Florida but has now become a pest. "They're very aggressive when they're defending their nest," he said. "They will attack other fish. If the native fish need that same territory to reproduce, tilapia can exclude them from that resource and negatively impact their reproduction."

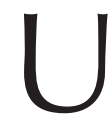
Itimately, however, early detection and thorough monitoring is the best defence against invasions. Daniel Janzen, an evolutionary biologist from the University of Pennsylvania (Philadelphia, PA, USA), is working on a gadget that could enable the development of a dense surveillance system for invasive pests, using an army of volunteers. His tool resembles a specieslevel 'tricorder', similar to that from the sci-fi franchise Star Trek, in which a character would use the portable device to detect life-forms and resources on an alien planet. Janzen said the idea of a tricorder has been around for decades and would be a useful tool to identify and monitor invasive species as well as any other plants and animals.
Since 1978, Janzen has been studying moth and butterfly caterpillars in the northwestern corner of Costa Rica. By 2003, he had built a database of 3,000 species out of an estimated 12,500 in this region. That year, he connected with geneticist Paul Hebert, a researcher from the University of Guelph in Canada and inventor of the 'DNA-barcoding' technique that uses short snippets of mitochondrial DNA to identify species. Their goal is to develop a handheld personal reader the size and cost of a pocket comb. Janzen and Herbert envision that their 'barcorders' would be used by farmers, game wardens, school children or anyone else.

\section{...the idea of a tricorder has been around for decades and would be a useful tool to identify and monitor invasive species as well as any other plants and animals}

"I can't think of any better way for anybody, everybody out there to be telling you whether invasive species are here, there and otherwise, than to have this device in their back pocket," Janzen said. "How many farmers and other outdoors people are there in North America? If every one of them had a barcorder and every time he saw a weird weed growing in his wheat fields, he just pulled a little chip off a leaf and stuck it in his barcorder that would tell the USDA or some other central agency, 'Ah! This plant grows there."'

Bott, in South Australia, agreed that such devices would be a great help to monitor the spread of invasive species. "We can't be everywhere at once sampling all these different areas. But having the ability to actually go down and test them on site would, in the future, really increase the throughput of our testing and make it a lot easier and possibly less expensive to test a wide range of species. It's not a fantasy. It's achievable."

\section{REFERENCES}

Ficetola GF, Miaud C, Pompanon F, Taberlet P (2008) Species detection using environmental DNA from water samples. Biol Lett 4: 423-425 Jerde CL, Mahon AR, Chadderton WL, Lodge DM (2011) "Sight-unseen" detection of rare aquatic species using environmental DNA. Conserv Lett [Epub 4 Jan] doi: 10.1111/j.1755-263X.2010. 00158.x

\section{Howard Wolinsky is a freelance journalist in Chicago, Illinois, USA.}

EMBO reports (2011) 12,310-313. doi:10.1038/embor.2011.40 